\title{
La dinámica familiar y estilos de crianza: pilares fundamentales en la dimensión socioafectiva*
}

\author{
Adriana María Gallego Henao \\ José Wilmar Pino Montoya*** \\ Mónica María Álvarez Gallego**** \\ Enid Daniela Vargas Mesa ${ }^{* * * * *}$ \\ Leidy Viviana Correa Idarraga $a^{* * * * * *}$
}

Recibido: 10 de septiembre del 2018

Evaluado: 4 de noviembre de 2018

Aceptado: 16 de enero del 2019

Citar como: Gallego Henao, A. M., Pino Montoya, J. W., Álvarez Gallego, M. M., Vargas Mesa, E. D., y Correa Idarraga, L. V. (2019). La dinámica familiar y estilos de crianza: pilares fundamentales en la dimensión socioafectiva. Hallazgos, 16(32), 131-150. DOI: https://doi. org/10.15332/2422409X.5093

\section{Resumen}

El objetivo del presente artículo es dar cuenta de los imaginarios y representaciones de familias construidos por niños y padres y su relación con la dimensión socioafectiva. El estudio se basó en un paradigma cualitativo haciéndose énfasis en la estrategia de investigación estudio de caso. Se utilizaron como técnicas de recolección de información la observación y la entrevista semiestructurada en los participantes, que fueron 9 niños y sus respectivos padres o cuidadores. Se obtuvo que los modelos educativos inciden en el desarrollo socioafectivo y en los diferentes comportamientos de los niños y se concluyó que los niños que están sometidos bajo modelos educativos autoritarios, tienden a aislarse del grupo social de referencia y aquellos que se educan bajo modelos educativos democráticos son propensos a ser más autónomos y logran socializar con mayor facilidad.

Palabras clave: familia, modelos educativos, socioafectividad.

\footnotetext{
Este artículo de investigación científica y de desarrollo tecnológico se deriva de la investigación Estructura y dinámica interna familiar con relación a la participación ciudadana, el cual fue financiado por la Vicerrectoría de Investigaciones de la Universidad Católica Luis Amigó, Sede Medellín, Colombia; para ejecutarse entre 2017 y 2018. El grupo de investigación al que se vincula el producto es Educación, Infancia y Lenguas Extranjeras.

** Magíster en Educación y Desarrollo Humano. Docente investigadora y coordinadora de la Maestría en Educación, Universidad Católica Luis Amigó. Medellín, Colombia. Correo electrónico: adriana.gallegohe@amigo.edu.co - ORCID: https://orcid.org/0000-0003-2952-1603

*** Doctor en Filosofía. Docente investigador de la Facultad de Educación y Humanidades, Universidad Católica Luis Amigó. Medellín, Colombia. Correo electrónico: Jose.pinomo@amigo.edu.co. - ORCID: https://orcid.org/0000-0001-9035-2058

**** Magíster en Salud Pública. Docente investigadora y coordinadora del campo de investigación, Facultad de Educación y Humanidades, Universidad Católica Luis Amigó. Colombia. Correo electrónico: monica.alvarezga@amigo.edu.co - ORCID: https://orcid.org/0000-0002-3894-0554

${ }^{* * * * *}$ Estudiante de Especialización en Docencia Universitaria; licenciada en Educación Preescolar. Integrante del semillero Historia, Infancia y Cultura, joven investigadora del programa Jóvenes Investigadores de la Universidad Católica Luis Amigó, Sede Medellín, Colombia. Docente del Jardín Infantil Pelusa. Correo electrónico: enid.vargasme@amigo.edu.co - ORCID: https://orcid.org/0000-0003-2228-2072

${ }^{* * * * * *}$ Licenciada en Educación Preescolar, Universidad Católica Luis Amigó, Sede Medellín, Colombia. Docente del Centro Educativo los Pioneros. MedeIlín, Colombia. Correo electrónico: leidy.correaid@amigo.edu.co - ORCID: https://orcid.org/0000-0001-9104-6933
} 


\section{Family dynamics and parenting styles: fundamental pillars in the socio-affective dimension}

\section{Abstract}

The objective of this article is to give an account of the imagiReceived: september 10, 2018 naries and representations of families built by children and paEvaluated: november 4, 2018 rents and their relationship with the socio-affective dimension. Accepted: january 16, 2018 The study was based on a qualitative paradigm, emphasizing the case study research strategy. The observation and the semi-structured interview were used as information gathering techniques in the participants, who were 9 children and their respective parents or caregivers. It was obtained that the educational models influence the socio-affective development and the different behaviors of the children, and it was concluded that the children who are under authoritarian educational models, tend to be isolated from the social group of reference and those who are educated under democratic educational models are likely to be more autonomous and manage to socialize more easily.

Keywords: family, educational models, socio-affective dimension. 


\section{A dinâmica familiar e estilos de criação: pilares fundamentais na dimensão socioafetiva}

Recebido: 10 de setembro de 2018

Avaliado: 4 de novembro de 2018

Aceito: 16 de janeiro de 2019

\section{Resumo}

O objetivo deste artigo é mostrar os imaginários e representações de famílias construídos pelas crianças e pais e sua relação com a dimensão socioafetiva. O estudo baseou-se em um paradigma qualitativo fazendo ênfase na estratégia de pesquisa de estudo de caso. Utilizou-se como técnicas de arrecadação de informação a observação e a entrevista semiestruturada nos participantes, que foram 9 crianças e seus respectivos pais ou cuidadores. $\mathrm{Ob}$ teve-se que os modelos educativos incidem no desenvolvimento socioafetivo e nos diferentes comportamentos das crianças e foi concluído que as crianças estão submetidas sob modelos educativos autoritários, tendem ao isolamento do grupo social de referencia e aqueles que se educam sob modelos educativos democráticos são propensos a ser mais autônomos e logram socializar com mais facilidade.

Palavras-chave: família, modelos educativos, socioafetividade. 


\section{INTRODUCCIÓN}

El Ministerio de Educación Nacional (1997) en los Lineamientos Curriculares de Educación Preescolar, expresa la importancia de los padres y cuidadores frente al desarrollo afectivo de los niños, quienes en sus primeros años se caracterizan por tener la facilidad, por ejemplo, de pasar de la risa al llanto y del llanto a la sonrisa; situaciones que son evidencia clara de que los niños ${ }^{1}$ son netamente emotivos; y que corresponde a los adultos cuidadores, como agentes socializadores, ayudarles a madurar en esta dimensión. Mieles y García subrayan que "la socialización es concebida como el proceso que permite el desarrollo de la identidad personal, así como la transmisión y aprendizaje de una cultura" (2010, p. 810); lo anterior significa que la familia como núcleo primario de socialización es la responsable de brindar las bases emocionales sólidas para que los niños adquieran habilidades y competencias para desenvolverse en la sociedad y afrontar el reto de resolver las diversas situaciones que se les presenten en el diario vivir.

Gracias a la solidez de la dimensión socioafectiva, que la estructura la familia o los cuidadores, se inicia la construcción de la identidad, el reconocimiento del yo, se afirma la autoimagen, se desarrolla la autoestima y el autoconcepto. Estos autos son esenciales en las relaciones humanas y en la forma como el niño se instala en el mundo; asimismo, los autos están mediados por los vínculos y en estos, las manifestaciones de

En este texto se hablará solo de niños por facilidades en la escritura, en ningún momento se emplea con el ánimo de excluir a las niñas. En el término están también las niñas. afecto son puente clave para la configuración de la identidad.

Además, la socialización en la primera infancia se da gracias a los diferentes intercambios afectivos que se generan; en primera medida con la madre quien es la que generalmente cuida, aporta el lenguaje y descifra las necesidades de su hijo; luego de generado el lenguaje, se inicia la aparición de los intercambios comunicativos entre el niño y su cuidador, y con ello, aparecen las primeras reglas comunicativas y de comportamiento social. El desarrollo socioafectivo en estas interacciones juega un papel esencial debido a que potencia el desarrollo de los niños de manera integral. Cuando la familia le brinda al niño seguridad y permite que exprese todos sus sentimientos, pensamientos y emociones, esta contribuyendo a que ese ser que se encuentra en desarrollo logre formarse como ser autónomo, libre e integral:

Es importante el cuidado, la orientación y la formación ofrecida por los padres y madres, cuidadores y cuidadoras, maestros y maestras o demás adultos significativos, quienes constituyen el soporte principal mediante el cual los niños y niñas desarrollan su identidad, en interacción permanente con la individualidad, las características personales y la autonomía creciente, que juegan un papel decisivo en el curso que tomarán sus vidas. (Mieles y García, 2010, p. 815).

Lo anterior, sugiere la dimensión socioafectiva como uno de los pilares fundamentales en el desarrollo armónico e integral de los niños, debido a que está estrechamente ligada a lo social, es decir, por su naturaleza necesita de otros para construir significados, 
experiencias y aprehender el mundo que los rodea; y la calidad en las interacciones les va a permitir desarrollar la capacidad para expresar sentimientos y pensamientos, no solo con las personas cercanas al núcleo familiar sino con cualquier ser humano que se encuentre a su alrededor y quienes le ayudan a definir su personalidad, es así que "la demostración de afecto por parte de los mayores será la primera piedra para ir formándose y para ir construyendo una personalidad sólida en componentes emocionales y actitudinales" (Sánchez, 2008, p. 4).

Richardson (1993), citado por Gallego (2012), subraya que los comportamientos de los niños están permeados por la relación y el vínculo que tejen los cuidadores, y por la “(...) estrecha vinculación emocional que se establece y mantiene entre el niño y aquellas personas de su entorno que más establemente interactúan con él, satisfacen sus necesidades, le aportan estimulación y responden a sus demandas e iniciativas" (Rangel, 2015, p. 163). Si bien, el apego va de la mano con la comunicación que se da entre las personas, este no necesariamente se relaciona con el hecho de pertenecer a un grupo familiar, sino que es parte de la relación que se establece entre dos o más personas en la que aprenden a conocer gustos, necesidades y son apoyo emocional el uno para el otro. Es así, que el apego es el vínculo que el niño crea con personas que a él le brindan seguridad emocional y quienes le ayudan a resolver sus necesidades, deseos e intereses; todo este tipo de acciones y vínculos son los que favorecen el adecuado desarrollo socioafectivo y la construcción de los imaginarios de familia.

Padres, madres, cuidadores y maestros deben tener especial cuidado en el cultivo de esta dimensión, debido a que es en los primeros años de vida donde se crea, construye y afianza su propia manera de ver el mundo y las cosas, de las interacciones que se tejan en el ambiente protector (familia) dependerá su proceso de socialización, la construcción de sus imaginarios y representaciones de familia, su comportamiento en los diferentes ambientes, así como su seguridad psicológica y el desarrollo socioafectivo. Al cultivar relaciones afectivas y de vincularidad con el niño, se favorecerá el desarrollo de competencias relacionadas con la capacidad para expresar sus emociones, el amor y el afecto de manera asertiva, oportuna y respetuosa, lo que se verá reflejado en una mejor relación con los demás.

\section{Metodología}

El estudio se llevó a cabo bajo el diseño cualitativo. El enfoque utilizado fue el hermenéutico y la estrategia de investigación el estudio de caso, partiendo de la premisa de que la "realidad (asunto ontológico) es construida por las personas involucradas en la situación que se estudia; y aunque las versiones de los mundos sean personales, estima que las construcciones no son completamente ajenas, sino que se parecen, tienen puntos en común" (Ceballos, 2009, p. 416), en otras palabras, los participantes narraron sus experiencias vitales y con estas se pudo tener un acercamiento a los imaginarios de familia construidos por los niños así como a la comprensión del desarrollo de su dimensión socioafectiva.

\section{CONTEXTO de LA INVESTigación}

El contexto de la investigación fue el Club Rotario de Envigado. Esta institución presta 
servicios de atención integral educativa, recreativa y nutricional a la población de escasos recursos del municipio. Actualmente tiene ciento cinco (105) niños inscritos, divididos en cinco grupos: párvulos; prejardín A y B, jardín A y B. Cada uno de estos grupos cuenta aproximadamente con veintidós niños. Con respecto a la planta docente, la institución cuenta con cinco: una normalista, tres licenciadas y una administradora educativa.

\section{Participantes}

Para el estudio se eligieron 9 niños del grupo prejardín B, con edades entre los tres y cuatro años y sus respectivos padres o cuidadores, a quienes y al inicio de la investigación, se invitó y se socializó el proyecto, luego se procedió con la firma del consentimiento informado, en el que se dejó claro que la información que suministraran como participantes de la investigación era confidencial, y su utilización solo se tomaría con fines académicos; además, se les aclaró que podían retirarse del estudio cuando lo desearan. De igual manera, se explicó que los nombres de los participantes se mantendrían en confidencialidad con el fin de proteger la identidad de ellos y la de sus hijos.

\section{Instrumentos para la recolección de la información}

Para la recolección de la información se aplicaron entrevistas semiestructuradas entendidas como la posibilidad de obtener información relevante de los padres o cuidadores. De esta participaron ocho padres de familia y una abuela. Así mismo, se aplicó una encuesta a este mismo grupo de participantes con el fin de obtener información demográfica y de la tipología familia. Con los niños y padres se realizaron cuatro talleres pedagógicos materializados en técnicas interactivas de la investigación social que, según García González, Ghiso y Quiróz (2003), se entienden como la posibilidad de acercamiento a las vivencias, experiencias e historias personales de los participantes. También se acudió a la observación no participante que, de acuerdo a Ander-Egg (1995), es aquella en la cual el investigador asume la posición espectadora sin involucrarse con los participantes del estudio. De esta técnica se derivaron 10 observaciones en los espacios en los que interactuaban los niños-docentes. La información recolectada fue registrada en videos, fotos, audios y diarios de campo. Una vez se finalizó el trabajo de campo se procedió a la trascripción, depuración y sistematización de la información.

\section{Análisis de la información}

Para el análisis de la información se construyó una matriz categorial, la cual permitió organizar y clasificar la información partiendo de los ejes principales (categorías) a las unidades más pequeñas (subcategorías); esto llevó a identificar los temas más recurrentes o relevantes y las ideas más reiteradas provenientes del trabajo de campo. Seguidamente se procedió al análisis del fenómeno-objeto a partir de los objetivos en cruce con los relatos de los participantes y los aportes de los teóricos revisados en el marco teórico. Finalmente, con esta información organizada, tematizada, sistematizada y analizada, se procedió a la escritura de los siguientes resultados y discusión. 


\section{Resultados Y Discusión}

\section{Imaginarios de familia: desde las voces de los niños y las niñas}

Para García y Ortiz (2013) la familia trasciende la consanguinidad y se construye en un sentido más amplio, en el que el afecto, la convivencia, las relaciones cotidianas, el compartir y construir una historia vienen a definir quién pertenece o no al grupo familiar; es así que considerar estar dentro de una familia implica aceptar el conjunto de situaciones que rodea a sus participantes, comprender la diversidad al interior de esta $\mathrm{y}$ apoyarse, pese a las diferencias y experiencias que existan en su interior.

Es así que en la familia se construyen las primeras experiencias vinculares del niño. Estas experiencias le proporcionan, o por lo menos se espera que le brinde, el bienestar para su desarrollo armónico e integral. Sin embargo, las dinámicas sociales, culturales, económicas y familiares han llevado a que el concepto de familia y las relaciones que se tejen en esta se transforme de generación en generación; al respecto refieren García y Ortiz, "el concepto actual de familia permite tener una mirada más compleja y amplia e incluir las diferentes tipologías familiares, teniendo en cuenta los cambios y transformaciones que se han dado en la familia en los últimos años" (2013, p. 81). Por ejemplo, para el niño $1^{2}$ participante de la investigación, los lugares y las cosas son parte de su familia, y esto se evidenció cuando él afirmó: "mi familia es la finca, mi tío y todos los que viven en ella porque ellos me hacen muy feliz" (niño 1, taller realizado el 14 de marzo

2 Los nombres de los participantes se omiten con el fin de proteger y salvaguardar su identidad. del 2017), lo que en palabras de Anzaldúa se comprende que "lo imaginario alude a imágenes o a representaciones, mientras que otros destacan su carácter de significación y de construcciones de sentido" (s. f., p. 1) que se le da a la realidad. La afirmación del niño 1 evidencia que las construcciones de familia que posee están relacionadas con sus experiencias afectivas y con el entorno en el que vive; en tanto las personas y las cosas cobran sentido no porque existan sino por su experiencia vital con ellas, es decir, el imaginario expuesto por el niño 1 está relacionado con las elaboraciones simbólicas (García, 2007) que ha construido a partir de los objetos concretos con los que tiene a su alrededor y que representan gratificación.

Sin embargo, para algunos niños participantes sus imaginarios de familia estaban relacionados con el deseo o con la proyección de lo que debería ser la realidad que ellos desean fuere su familia. Así lo expresó otra participante: "mi familia es mi hermanita, mi tía, mi mamá y mi papá, aunque ya se separó de mi mamá, pero yo lo sigo queriendo" (niña 2, taller realizado el 14 de marzo del 2017.)

Para la niña 2, por ejemplo, su imaginario está atravesado por la experiencia afectiva, ella entiende y expresa que, aunque exista una ruptura en el vínculo marital, esta ruptura es con la figura materna, no con ella como hija. Y aunque el padre no esté presente físicamente en la cotidianidad del hogar, sí está presente en su imaginario, en su sentir, en su deseo. Para otros niños, el imaginario está relacionado con la estructura familiar: "mi familia es mi abuela, mamá, papá y yo" (niña 3, taller realizado el 14 de marzo del 2017); "mi familia es mi mamá y mi hermanito; mi papá no porque no vive 
con nosotros" (niña 4, taller realizado el 14 de marzo del 2017). Este relato permite observar que la niña pasa a la representación de familia, y que esta representación está relacionada con las nuevas configuraciones de la misma que se tiene en la actualidad. Es así que se puede señalar que acorde a cada cultura y contexto social, se reconoce que existen diferentes maneras de constituir y formar una familia, la cual necesariamente no está ligada por lazos sanguíneos, sino determinada por vínculos afectivos y subjetivos que se construyen al interior de esta. Por lo tanto, estos imaginarios que aparecen están relacionados con la estructura de la familia y con el vínculo que se teje entre los integrantes de esta.

Para el caso de la niña 3 se resalta una composición familiar que responde a la familia extensa, entendida por el Observatorio de Políticas de las Familias como aquellas que están "conformadas por un hogar nuclear más otros parientes" (OPF, 2015, p. 10). Para el caso de la niña 4, la composición que refiere es una familia monoparental, la cual está compuesta por uno de los padres con sus hijos; en este último aspecto también se resalta que la niña 4 además de construir su imaginario sobre la composición familiar, nombra la ausencia del padre como elemento esencial en su imaginario de familia. Al respecto señalan De León y Herazo: “[los imaginarios son] construidos a partir de las vivencias y experiencias, pero al mismo tiempo de las características del ambiente, las informaciones que circulan en la vida diaria, la educación y la comunicación social" (2009, p. 75), la narración de estos hechos permite comprender las situaciones de la vida familiar. Pinto agrega que el imaginario es:
El conjunto de significados que cobra la realidad en la vida de los seres humanos; durante el ciclo vital es claro que se presentan de manera constante acontecimientos que determinan de manera fundamental la construcción mental de los sujetos $\mathrm{y}$, por ende, se identifica allí su importancia; así, no solo transcurren los hechos, sino que se convierten en elementos que aportan a la generación de significados. (2015, p. 11).

Vemos entonces, que el significado de familia está relacionado con la calidad en las interacciones, en tanto existe la posibilidad de generar encuentros con el otro para compartir y comunicar sentimientos; así mismo, los imaginarios para el caso de los niños del estudio no solo aluden a las personas sino también a los lugares y a las experiencias vitales que tejen con el contexto social.

Por otro lado, es importante aclarar que al hablar del imaginario no se puede retomar un significado global, por ejemplo, para Castoriadis citado por Anzaldúa, "lo imaginario no es la imagen de algo, sino la creación incesante e indeterminada de figuras, formas, imágenes, que actúan como significaciones, en tanto que a partir de ellas las cosas, los hechos, los procesos, cobran sentidos" (s. f., p. 5). Dentro de este marco, se evidencia que el imaginario se manifiesta de formas distintas en todas las personas; darle o encontrarle un significado limitaría la capacidad que tienen los seres humanos de crear e imaginar, convirtiéndose esto en contradictorio.

Por otro lado, se resalta que en ocasiones los niños por el deseo de tener una familia desde la visión tradicional construyen imaginarios que no se corresponden con su 
realidad, como es el caso de la niña 6 quien señala: “mi papá se separó de mi mamá, vive en una casa lejos... yo voy a visitarlo y a saludarlo" (niña 6, taller realizado el 14 de marzo del 2017). Al cruzarse esta información con la aportada por la madre, se encontró que la niña 6 no conoce a su progenitor, sin embargo, se infiere que ella, para matizar sentimientos de frustración y posiblemente de soledad, crea el imaginario de familia desde el vínculo afectivo con su padre quien, según la madre, nunca ha estado presente en el proceso de crecimiento y desarrollo de la niña. Es así como se deduce que, aunque el padre no ha estado presente en su vida, la niña creó una imagen de él y este existe porque ella desde el discurso le ha dado un lugar en su vida.

Los imaginarios no tienen una verdad $a b-$ soluta, es así como los niños crean a partir de diferentes experiencias, imaginarios, los cuales responden a deseos o representaciones que se encuentran inmersos en su cotidianidad. En suma, la mayoría de los niños poseen un imaginario de familia transversalizado por el afecto, el acompañamiento y la presencia de las figuras materna o paterna en la que llamamos casa. Se puede notar entonces, que la concepción de familia varía según sean los vínculos, las vivencias, las conexiones que se logren entre sus miembros, así como del momento histórico que viva la familia.

\section{Representaciones de familia: desde las voces de las madres}

Para Moscovici, la representación “es mediatizada por el lenguaje” (1984, p. 25), en tanto este permite transmitir nuestra historia, es decir, nuestras palabras reflejan cómo nos hemos construido y lo que hemos construido en el tiempo y en el espacio. En coherencia con lo dicho, es importante rememorar que la madre, históricamente desde su rol de cuidadora, transmite al niño el mundo y todo lo que hay en él; y el niño aprende y a su vez reproduce lo aprendido. Es por ello que se afirma que el ser humano es producto de lo que los padres o cuidadores hacen de él, y la forma como el adulto se posiciona en el mundo depende de las bases recibidas en la infancia, convirtiéndonos en una extensión de los padres o cuidadores.

Abric (1976) subraya que las representaciones están marcadas por dos elementos, a saber: las actitudes y las relaciones. Ambos elementos conllevan a que se le dé sentido a la imagen social que existe en el mundo y que se construye cognitivamente gracias a otro que existe y que lleva a que se perpetúe. Lo anterior, se puede ilustrar a partir del siguiente relato de una de las participantes, cuando expresa que:

La familia es la conformación de un grupo de personas, que representan la autoridad, estas personas son ejes a seguir y son los pilares que sostienen económica, afectiva, religiosamente a los demás integrantes de la familia; pienso, además, que este grupo de personas no tienen que ser necesariamente papá, mamá e hijos, para hablar de familia como era antes. (Entrevista n. ${ }^{\mathrm{o}}$, realizada el 8 de marzo del 2017).

El relato de la participante permite inferir que la representación de familia que ella posee hace alusión a tres elementos importantes: la familia como institución social, la cual no necesariamente está conformada por unión marital avalada por la Iglesia; la familia como soporte económico y la familia como grupo de 
apoyo. Wartemberg (1983), citado por Parra (2005), expresa que "la familia es un grupo con relaciones de dependencia personal y no contractual (afinidad, consanguinidad y amistad) que se articula como unidad a través de decisiones y acciones tendientes a satisfacer necesidades vitales" (p. 12), es por esto que cada individuo tiene unas características que lo definen y lo diferencia de los demás.

Para Vasilachis, las representaciones son “construcciones simbólicas individuales y/o colectivas que los sujetos crean o a las que los sujetos apelan para interpretar el mundo, reflexionar sobre su propia situación, la de los demás, determinar el alcance y la posibilidad de su acción histórica" (2003, p. 268). Es así que se puede afirmar que las representaciones o estas imágenes de familia también están asociadas con las experiencias y el contacto, el vínculo y cercanía que se teje con los otros; así lo expresa una madre en su relato: "mi hijo le demuestra más afecto a mi suegra, su abuela, todo el tiempo la menciona, siempre quiere estar con ella, puesto que ella le cumple todos los caprichos, aunque mi esposo y yo sabemos que la quiere, en gran parte es por eso y porque lo cuida" (entrevista n. ${ }^{\circ} 2$, realizada el 8 de marzo del 2017).

La representación es "una representación de algo y de alguien" (Jodelet, 1984, p. 475). Lo que significa que, siempre que se haga alusión a una imagen mental (representación), esta estará asociada, por un lado, a un acontecimiento o personaje y por el otro, a un contenido, opinión o actitud. Una participante manifiesta que para ella, "la familia es importante porque es la base, es el apoyo en situaciones de la vida, es la primera fuente de iniciación a la personalidad y a la cultura... porque todos salimos a la calle $y$ somos diferentes, y eso es lo que nos califica en la sociedad" (entrevista n. ${ }^{\circ}$ 9, realizada el 10 de marzo del 2017). El relato expuesto, está en sintonía con lo expresado por Domínguez, al señalar que "la familia es socializante porque transmite unas formas de pensar, sentir y actuar, valores y actitudes que se han recibido de la tradición en la que se está inmerso" (2007, p. 226).

Para Potter, las representaciones son tomadas para realizar acciones individuales, es decir, "las descripciones pueden intervenir en las acciones de muchas maneras, por otro lado, muchas de ellas pueden limitarse a unas culturas determinadas y a unos contextos dentro de estas culturas" (1998, p. 225). Lo anterior significa que el ser humano construye imágenes mentales, las incorpora a sus experiencias y desde estas realiza descripciones del mundo que le permiten estar e interactuar con los otros: "para mí, la familia es el núcleo más importante de la sociedad, el cual debe permanecer unido y en ella es donde se expresa el amor, amor que luego se dará a la sociedad" (entrevista n. ${ }^{\circ}$, realizada el 9 de marzo del 2017). Otra participante señaló: "considero mi hogar como una familia porque en ella hay mucho amor, comprensión y todos somos muy compartidos con lo poco que tenemos" (entrevista n. ${ }^{\text {o }}$ 3, realizada el 28 de febrero del 2017).

Las familias participantes en sus relatos y discursos dejan ver que sus representaciones de familia están asociadas a sus experiencias socioafectivas con los integrantes del grupo y a la calidad en las interacciones entre los miembros del grupo familiar. De igual manera, las madres manifestaron que 
la familia es la encargada de pasar de generación en generación la cultura; así lo refiere otra participante: "para mí, la familia es el pilar fundamental de toda sociedad, es una base donde están los cimientos para aprender valores, principios $\mathrm{y}$, además, también es la familia quien educa" (entrevista n. ${ }^{\circ}$ 6, realizada el 9 de marzo del 2017). Al respecto, Minuchin (1994), citado por Scarpati, Pertuz y Silva (2014, p. 229), plantea que "la familia es un grupo natural que en el curso del tiempo elabora pautas de interacción que constituyen la estructura familiar, esta rige el funcionamiento de los miembros de la familia, define conductas y facilita su interacción recíproca". Por su parte, Posada, Gómez y Ramírez afirman que la familia en sí misma genera un sinnúmero de relaciones "integradas en forma principalmente sistémica, por lo que es considerada un subsistema social que hace parte del macrosistema social denominado sociedad; esas relaciones son consideradas como un elemento fundamental en el proceso de desarrollo de la personalidad" (2004, p. 16); "la familia constituye entonces una imagen $\mathrm{y}$ un ejercicio permanente en la vida humana que se caracteriza por sus relaciones de intimidad, solidaridad y duración y es, por lo tanto, un agente estabilizador" (Horwitz, Florenzano y Ringeling, 1985, p. 145).

Las representaciones de familia para los padres, se sustentan en primer lugar en las personas con quienes viven, y en segunda medida referencian la sociedad, es decir, los participantes resaltaron que la familia como primer agente de socialización lleva a que el niño se construya como ser social para luego salir a la sociedad y allí tejer interacciones que le permitirán avanzar en su desarrollo psicológico, emocional y relacional, entre otros. Se resalta, además, que los relatos dejan entrever que el vínculo, el amor, la confianza y la comprensión son considerados como la base fundamental para el desarrollo infantil. En sintonía con lo dicho, "la familia es socializante porque transmite unas formas de pensar, sentir y actuar, valores y actitudes que se han recibido de la tradición en la que se está inmerso" (Domínguez, 2007, p. 226). En este sentido, estar dentro de una familia es importante, es allí donde se aprende y se construyen significados, con los cuales las personas elaboran bases para integrarse en la sociedad, de este modo se hace notable cómo la familia es un apoyo para afrontar las diferentes situaciones que se presentan a lo largo de la vida, debido que ella es un soporte para cada miembro que la conforma.

Ahora bien, para los participantes, el pertenecer a una familia, va más allá de hacer parte de un grupo de personas (hogar) ${ }^{3}$, por lo tanto, es la fuente que transmite la cultura y por medio de ella se comienza a formar la personalidad, lo que más adelante nos cataloga en una sociedad, a lo que Osorio y Álvarez (2004) ratifican que: "la familia es responsable de la socialización, y de las implicaciones que esto conlleva, las cuales incluyen: las normas, valores, creencias, prejuicios, mitos y tabúes de la sociedad para reconocer sus propios límites y respetar el espacio de los demás" (p. 20). Reconocimiento que le permite al ser humano convivir sanamente con los otros.

En suma, las representaciones desde el punto de vista de los padres, están asociadas a

3 Según la Real Academia Española, hogar es entendido como una casa o domicilio, donde un grupo de personas emparentadas viven juntas. 
tres elementos: el primero, las actitudes relacionadas con el cuidado y la crianza de los niños, aspectos que se ven revertidos en el desarrollo adecuado de la dimensión socioafectiva; segundo, el tiempo de calidad que se les brinda, asunto que lleva a que los hijos puedan insertarse en la cultura y responder a las demandas de esta desde relaciones vinculantes sanas y, tercero, está relacionada con la conformación de la misma familia, dejando abierto que en la actualidad la estructura tradicional ha cambiado y que, las madres, desde sus mismas experiencias como mujeres solteras o divorciadas, también son una familia con sus hijos o demás miembros; familias en las cuales asimismo se puede hacer un cultivo de la dimensión socioafectiva.

\section{Estilos educativos parentales y su influencia en la dimensión socioafectiva}

Históricamente la familia ha sido el contexto, por excelencia, responsable de la crianza, pero más que un tema de responsabilidad, es y ha sido el lugar privilegiado para formar el carácter, la personalidad y la autonomía de los hijos, así como el escenario propicio para el desarrollo de habilidades y destrezas para comunicar, interactuar y razonar. Para nadie es innegable que los adultos cuidadores desempeñan un papel esencial en la vida de la infancia, especialmente en los primeros años, no obstante, tampoco se puede negar que niños y niñas no reciben única y exclusivamente influencia de su padres o cuidadores, ellos inclusive desde antes de nacer están influenciados por otros ambientes y actores de quienes aprenden. En este sentido, afirma Rich: "la educación no es algo que los padres hagan a los hijos, sino algo que padres e hijos hacen conjuntamente" (2002, p. 53). Lo anterior significa que los padres actúan, los hijos aprenden y viceversa; este ciclo que constantemente se repite al interior marca las formas de relación en el hogar, o dicho de otra forma:

La dinámica familiar se puede interpretar como los encuentros entre las subjetividades, encuentros mediados por una serie de normas, reglas, límites, jerarquías y roles, entre otros, que regulan la convivencia y permite que el funcionamiento de la vida familiar se desarrolle armónicamente. Para ello, es indispensable que cada integrante de la familia conozca e interiorice su rol dentro del núcleo familiar, lo que facilita en gran medida su adaptación a la dinámica interna de su grupo. (Gallego, 2012, p. 333).

Así mismo, el equilibrio en las características de la dinámica familiar como "los roles, los límites, las jerarquías y los espacios" (Arés, 1990, p. 571) presentan conflictos que en ocasiones llevan a que la dinámica familiar se torne caótica. Al respecto, señalan $\mathrm{Vi-}$ veros y Arias (2006, p. 6) que "la dinámica familiar hace referencia a la movilidad que se da en el clima relacional que construyen los integrantes de la familia para interactuar entre ellos mismos y con el contexto externo". En este sentido, Cifuentes, Massiris y Ruiz (1998) señalan que las dinámicas familiares son

[...] todas aquellas relaciones o aspectos que se dan al interior del grupo familiar que le permiten a los miembros, interactuar en cada uno de los subsistemas a través de diferentes procesos como la comunicación, los roles, las normas, 
y relaciones aflorando sentimientos, emociones, ansiedades y conflictos, estableciéndose una interacción con aspectos de su entorno como el medio ambiente, la educación, la cultura, la religión, la política, la comunidad y la sociedad en general; en donde cualquiera de estos aspectos suceden individual o grupalmente en la familia, afectando a todos sus integrantes. (P. 48).

Puede decirse entonces, que la tarea de ser padre o madre no es fácil, es un trabajo que en muchas ocasiones implica improvisación, en tanto a nadie le enseñan destrezas y habilidades específicas para situaciones particulares que se presentan en la cotidianidad de la familia; pero que según el estilo educativo que se implemente en la dinámica familiar, esta tarea de formación puede llevar a formar hombres y mujeres seguros, íntegros y felices. Es así que a estos modos de ser y de actuar "ante situaciones cotidianas, la toma de decisiones o la resolución de conflictos" (Torío, Peña y Rodríguez, 2008, p. 153) con respecto a los hijos se les denomina estilos educativos. Para Coloma, son “esquemas prácticos que reducen las múltiples y minuciosas prácticas educativas paternas a unas pocas dimensiones, que, cruzadas entre sí en diferentes combinaciones, dan lugar a diversos tipos habituales de educación familiar" (1993, p. 48). Vemos entonces, que en la familia se exponen modelos con los que se espera modelar comportamientos, actitudes y valores en sus integrantes. A continuación, se presentan los resultados de este estudio con respecto a los tres estilos educativos propuestos por Coloma: autoritario, democrático y permisivo y su relación con la dimensión socioafectiva.
Con relación al modelo educativo autoritario, se resalta que los padres aprecian y buscan la obediencia, el orden y la sumisión por parte de los integrantes del hogar. Este estilo educativo se observó en algunos discursos de los padres al referir: "me parece que la figura paterna es muy importante, debido a que esta da la autoridad, ya que las mamás son permisivas... pienso que los hijos no tienen prioridad, si la regla está puesta así es y se debe cumplir" (entrevista n.. 5, realizada el 10 de marzo del 2017). En esta perspectiva, el participante da a conocer el rol que él asume dentro de su familia, remitiendo la figura de autoridad solo al género masculino. No obstante, en la actualidad se puede observar que las prácticas de crianza y con ello las configuraciones familiares han ido cambiando de generación en generación; lo que significa un nuevo aire para la familia y un cambio en los paradigmas relacionados con la crianza, la educación, la cultura y la visión de lo femenino y lo masculino. Hoy, en algunas familias las funciones de proveer el sustento económico, el cuidado de los hijos y demás tareas que se desempeñan en el hogar, no recaen en un solo miembro, sino en la pareja como tal, o en su defecto, en todos los integrantes del núcleo familiar. Al respecto, Rico (1999) plantea que “el padre ya no se percibe como único proveedor económico de la familia, ni el único representante legal y guardián de sus hijos, a la vez que la madre deja de ser vista como la exclusiva responsable de proveer cuidados y atenciones domésticas al grupo familiar" (p. 115). Es así que la familia con el transcurrir de los años ha tenido transformaciones tanto en su estructura como en su dinámica interna, esto se ha visto reflejado en los roles que hay dentro de ella. 
Ahora bien, en el modelo autoritario, se busca mantener al hijo en un estado de subordinación de tal manera que se minimiza la autonomía, la capacidad para tomar decisiones y la libertad de expresar los pensamientos, sentimientos y necesidades. En este tipo de estilos, la palabra del otro, el hijo, queda invisibilizada porque lo que se busca es un "adecuado comportamiento" según el modelo que se espera por parte del padre. Según Casas (1988), este tipo de modelos lleva a que en el niño se presenten los siguientes comportamientos: "no confía en sí mismo, solo en las figuras autoritarias. Se afectan su capacidad de juicio y razonamiento porque se convencen de que la opinión de los padres es la mejor. La autoestima baja" (p. 14).

Al compararse lo expuesto por Casas (1988) con las observaciones realizadas en el aula de clase, se destaca el comportamiento del niño 5, quien en los espacios de socialización se muestra tímido e inseguro al relacionarse con sus pares; es temeroso cuando lastima a algún compañero sin culpa, y al momento de realizar las actividades de clase constantemente busca la aprobación de la maestra, preguntando: "profe, ¿me quedó lindo? ¿Es así? ¿Te gusta?" (diario de campo n. ${ }^{\circ}$, realizado el 6 de febrero del 2017).

El estilo educativo basado en el autoritarismo es el que hace más daño a la dimensión socioafectiva de los niños, debido a que son personas que carecen de autonomía y seguridad para tomar decisiones, estos niños presentan baja autoestima y las habilidades sociales son pocas precisamente por su inseguridad para relacionarse; además son poco comunicativos y afectuosos (MacCoby y Martin, 1983; Dornbusch, Ritter, Leiderman, Roberts y Fraleigh, 1987; Baumrind,
1996; Belsky, Sligo, Jaffee, Woodward y Silva, 2005).

Con respecto al modelo permisivo, los padres favorecen altos niveles de autonomía para sus hijos siempre y cuando su bienestar físico no se ponga en riesgo. Los adultos cuidadores generalmente tienen un temperamento dócil y afirmativo ante el comportamiento del niño; de igual manera no son exigentes con respecto a los deberes que se deben cumplir en el hogar, les cuesta marcar los limites llevando con ello serios problemas en términos de socialización. Veamos el siguiente relato de una participante: "yo como mamá soy muy permisiva, dejo que ella haga lo que quiera... a veces la animo para que haga sus actividades, pero también se las hago cuando empieza a hacer pataleta, llora o me ignora, ahí es cuando le ayudo" (entrevista n. ${ }^{\circ}$ 6, realizada el 9 de marzo del 2017).

Del relato se puede inferir que al ceder como padres frente a las demandas de los niños y al no tener límites y normas claros, se generan efectos negativos en la dimensión socioafectiva de ellos, en tanto el mensaje que se les envía es que son discapacitados mentalmente, que no tienen las competencias y herramientas para hacer las cosas por sí mismos $\mathrm{y}$, además, lentamente se convierten en pequeños emperadores a quienes se les debe obedecer. De igual manera, este estilo educativo lleva a que los niños sean dependientes y con tendencia a altos niveles de inmadurez y poco éxito personal (Steinberg, Elmen y Mounts, 1989; Lamborn, Mounts, Steinberg y Dornbusch, 1991; Banham, Hanson, Higgins y Jarrett, 2000).

Las consecuencias que conlleva un estilo educativo permisivo son las siguientes: 
“tienden a centrarse en sí mismos, se hacen demandantes e incapaces de tomar en cuenta a los otros, esperan que sus caprichos sean siempre satisfechos. No crecen en responsabilidad personal y autodisciplina. Tienen problemas de ajustarse a normas sociales" (Casas, 1988, p. 15). Al respecto, señala una participante: "en la casa no tiene un buen comportamiento, en algunas ocasiones me expresa que quiere ayudar a realizar el aseo de la casa y daña lámparas, raya paredes, ella en casa daña y bota todo" (entrevista n. ${ }^{\circ}$ 6, realizada el 9 de marzo del 2017). Arés, citado por Herrera (2000), afirma que:

Si los roles, los límites, las jerarquías y los espacios están distorsionados, lo más probable es que ello altere todo el proceso de comunicación e interacción familiar; por tal motivo el tema de la comunicación no puede ser visto desligado de estos procesos. (P. 571)

El establecer normas claras, implica al grupo familiar en esta construcción favorecer la interiorización de las mismas y generar un adecuado clima familiar, en tanto que esto permite que se cumplan las reglas sin perjudicar o incomodar a otra persona. Para García (2007, p. 8), "construir colectivamente las normas permite que todos los participantes (niños y adultos) las internalicen, valoren su función y se corresponsabilicen del proceso y de los resultados que se quieren lograr" dentro de este marco. Considerar las normas como hábito de crianza es apostar por un ambiente propicio para la familia, además dichas normas deben ser claras y construirse en conjunto con cada miembro del hogar, brindado la posibilidad de una participación activa. Gordillo (2003), citado por Sánchez (2008), resalta que:
La familia [...] como un sistema gobernado por reglas, la mayoría no escritas ni abiertamente expresadas; son inferencias que los miembros de la familia hacen respecto a las pautas de conducta que observan a su alrededor. De esta forma, plantear armónicamente las reglas que orientan y dirigen a la familia será de un gran valor para lograr la utilidad de las mismas. (P. 4).

En la entrevista $n .{ }^{\circ}$ 6, la niña sabe que con llanto, pataleta o mirada maneja a la madre, estas son estrategias de manipulación que usan los niños para lograr sus objetivos. La madre, por su parte, deja a su hija en libertad y autonomía para hacer y decidir; lo que significa que la heteronomía, los roles y las jerarquías desaparecen.

Con relación al estilo educativo democrático, este se caracteriza porque los padres tienden a buscan que los hijos obedezcan, pero desde el razonamiento y la negociación. Ellos esperan que sus hijos se acoplen a las reglas y normas desde posturas maduras y razonadas. Asimismo, existe un reconocimiento de los derechos y deberes que poseen tanto padres como hijos; se hace hincapié en el diálogo y en las responsabilidades consigo mismo, con el otro y con lo otro. Este estilo educativo se concreta en los discursos de los participantes cuando afirman:

No sé a qué se deba que mi hijo tenga un buen comportamiento, no creo que haya algo en específico, en parte puede ser a la buena comunicación y al explicarle qué es lo bueno y lo malo. (Entrevista

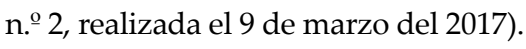

Yo la animo a que coma sola, a ponerse la pijama... y cuando son tareas le digo 
que es su responsabilidad, yo le ayudo con lo que ella no pueda hacer, constantemente estoy pendiente, pero si es su responsabilidad la dejo que lo haga. (Entrevista n. ${ }^{\circ}$, realizada el 3 de abril del 2017).

Vemos en los relatos que se buscan el desarrollo autónomo y la independencia, así como el desarrollo de competencias sociales,

Ella siempre ha sido muy autónoma, hace sus propias cosas, sin que nadie la ayude, cuando está pintando y la quiero ayudar, no deja y me dice "mami yo ya sé", en ocasiones sí me pide ayuda porque no sabe algo, pero en general lo hace todo ella sola. (Entrevista n. ${ }^{\circ}$, realizada el 6 de abril del 2017).

Este tipo de estilos educativos favorece la dimensión socioafectiva de los niños cultivando en ellos la capacidad de ponerse en el lugar del otro, les permite desarrollar comportamientos empáticos, tener una autoestima elevada y suelen ser más interactivos, amorosos e independientes (Dornbusch, Ritter, Mont-Reynaud y Chen, 1987; Chao, 2001; Warash y Markstrom, 2001; García, Pelegrina y Lendínez, 2002; Gfroerer, Kern y Curlette, 2004; Winsler, Madigan y Aquilino, 2005).

\section{Conclusiones}

Las familias de la investigación se encuentran dentro de tres tipologías: nuclear, extensa y monoparental. A lo largo de la investigación se evidenció que la tipología de familia no interviene en la dinámica familiar que tienen los padres entrevistados dentro de sus hogares, es así como en los resultados se observaron dos familias de tipología nuclear las cuales poseían rasgos diferenciadores en cuanto a los roles que se establecen dentro de la familia. Se aclara aquí, que la tipología no es determinante en la socialización de los niños; no obstante, el estilo educativo, la dinámica familiar y las prácticas de crianza sí influyen en los procesos de socialización. Por su parte, otros casos mostraron cómo la tipología familiar no influye en la socialización del niño en el medio, debido a que ellos demuestran tener independencia en acciones como: comer, ir al baño y jugar, además se evidenció en algunas familias que los niños son autónomos dentro del marco de la heteronomía.

En los relatos de los padres y en las voces de los niños se notan representaciones e imaginarios, respectivamente, que tienen sobre la familia. Los participantes señalaron que para ellos la familia no se basa solo en la cantidad de miembros que la conforman, sino que cada sujeto crea su representación de familia acorde a sus experiencias vividas en ella, "cada familia se narra y se conversa de forma diferente" (Builes, 2013, p. 11).

Es importante, además, que como familia se piense en la distribución adecuada de los roles y con ello en las responsabilidades que cada integrante va a desempeñar dentro del núcleo familiar, esto permite alivianar las cargas y el grupo podrá gozar de un clima de tranquilidad y serenidad. Al respecto, Herrera (2000, p. 570) refiere que para que exista "un adecuado funcionamiento familiar debe haber igualdad en la distribución de las tareas", es así que conocer el rol que cada persona tiene dentro de la familia, permite tener relaciones afectivas sanas, en tanto nadie se sentirá sobrecargado. Asimismo, vemos que existe un reacomodo en los roles y un cambio en el paradigma sobre el 
cuidado a los hijos y las responsabilidades que ello implican, y con lo anterior que el cuidado de los hijos no es exclusivo de la mujer sino que el hombre participa activamente de las tareas hogareñas, del cuidado de los hijos y de las necesidades económicas que se presenten en casa, lo que refleja unos roles compartidos de manera equitativa.

En suma, la autoridad ejercida desde el autoritarismo genera en los niños inseguridades llevándolos al aislamiento y a la búsqueda permanente de la aprobación del otro; aspecto que en la vida adulta se verá reflejado en jóvenes con poca capacidad para decidir frente a las situaciones de la vida cotidiana.

\section{REFERENCIAS}

Abric, J. C. (1976). Pratiques sociales et représentations. París, Francia: PUG.

Ander-Egg, E. (1995). Técnicas de investigación social. Buenos Aires, Argentina: Lumen.

Anzaldúa, A. E. (s. f.). Lo "imaginario" en la investigación educativa. En M. Ibarrola. IX Congreso Nacional de Investigación Educativa. Congreso llevado a cabo en El Consejo Mexicano de Investigación Educativa, A. C. y la Facultad de Educación de la Universidad Autónoma de Yucatán. México. DOI: https://doi.org/10.1016/j.resu.2015.12.001

Arés Muzio, P. (1990). Mi familia es así. La Habana, Cuba: Editorial Ciencias Sociales.

Baumrind, D. (1996). The discipline controversy revisited, Family relations. National Council on Family Relations, 45(4), 405-414. DOI: https://doi. org $/ 10.2307 / 585170$
Banham, V., Hanson, J., Higgins, A. y Jarre$\mathrm{tt}, \mathrm{M}$. (2000). Parent-child communication and its perceived effects on the young child's developing self-concept. Paper presented at the Australian Institute of Family Studies Conference. Sydney, Australia.

Belsky, J., Sligo, J., Jaffee, S. R., Woodward, L. y Silva, P. A. (2005). Intergenerational transmission of warm-sensitive-stimulating parenting: a prospective study of mothers and fathers of 3 years olds. Child Development, 76(2), 384-396. DOI: https://doi.org/10.1111/j.1467-8624.2005. 00852.x

Builes. M. (2013). Familia: colección aspectos claves. Medellín, Colombia: Panamericana Formas e Impresos.

Casas, F. G. (1988). La autoridad en la familia. En Brenes, A. O. Cúpula. 12-18. San José, Costa Rica. Recuperado de http:// www.binasss.sa.cr/bibliotecas/bhp/cupula/v11n23/art3.pdf

Ceballos Herrera, F. A. (2009). El informe de investigación con estudio de casos. $M a-$ gis. Revista Internacional de Investigación en Educación, 1(2), 413-423. DOI: https:// doi.org/10.11144/javeriana.m9-18.sccb

Cifuentes, A. J., Massiris, Y. y Ruiz, R. (1998). Características de la dinámica familiar en familias desplazadas por la violencia usuarias del proyecto hogares comunitarios de bienestar del sector Rancho Grande, Montería, Córdoba (trabajo de grado). Universidad del Norte, Barranquilla, Colombia. DOI: https://doi.org/10.18273/ revsal.v49n1-2017002

Coloma Medina, J. (1993). La familia como ámbito de socialización de los hijos. En J. M. Quintana Cabanas (coord.), Pedagogía familiar. Madrid, España: Narcea.

Chao, R. K. (2001). Extending research on the consequences of parenting style 
for Chinese-Americans and European-Americans. Child Development, 72(6), 1832-1843. DOI: https://doi. org/10.1111/1467-8624.00381

De León, R. y Herazo, E. (2009). Imaginarios sobre familia y pobreza de niños, niñas y jóvenes residentes en Orika. Islas del Rosario, Cartagena de Indias. Revista Palabrota, (10). DOI: https:// doi.org/10.32997/2346-2884-vol.10num.10-2009-134

Domínguez, X. (2007). Antropología de la familia. Madrid, España: Estudios y ensayos, Bac.

Dornbusch, S. M., Ritter, P. L., Mont-Reynaud, R. y Chen, Z. (1987). Family decision making and academic performance in a diverse high school population. Journal of Adolescent Research, (5), 143-160. DOI: https://doi.org/10.11 77/074355489052003

Dornbusch, S. M., Ritter, P. L., Liederman, P. H., Roberts, D. F. y Fraleigh, M. J. (1987). The relation of parenting style to adolescent school performance. Child Development. 58(2), 1244-1257. DOI: https://doi.org/10.1111/j.1467-8624.1987. tb01455.x

Gallego, A. M. (2012). Recuperación crítica de los conceptos de familia, dinámica familiar y sus características. Revista virtual Universidad Católica del Norte, (35), 326-345. En línea. Recuperado de http://www.redalyc.org/ pdf/1942/194224362017.pdf

García Linares, M. C. C., Pelegrina, S. y Lendínez, J. (2002). Los estilos educativos de los padres y la competencia psicosocial de los adolescentes. Anuario de Psicología, 33(1), 79-95. DOI: https://doi. org/10.1174/021037002317417796
García, J. M. y Ortiz, L.C (2013). Familia: colección aspectos claves. Medellín, Colombia: Panamericana Formas e Impresos.

García, N. (2007). ¿Qué son los imaginarios y cómo actúan en la ciudad? Revista Eure. 33(99), 89-99. DOI: https://doi. org/10.4067/s0250-71612007000200008

Posada Díaz, Á., Gómez Ramírez, J. F. y Ramírez Gómez, H. (2004). El niño sano. Bogotá D. C., Colombia: Médica Panamericana.

Gfroerer, K. P., Kern, R. M. y Curlette, W. L. (2004). Research support for individual psychology's parenting model. Journal of Individual Psychology, 60(4), 379-388.

Herrera, S. P. (2000). Rol de género y funcionamiento familiar. Revista de Medicina General Integral, (16), 568-573. En línea. Recuperado de http:/www.bvs.sld.cu/ revistas/mgi/vol16_6_00/mgi08600.pdf

Horwitz, C. N., Florenzano, U. R., y Ringeling, P. I. (1985). Familia y salud familiar, un enfoque para la atención primaria. Boletín de la Oficina Sanitaria Panamericana, (2), 144-145. Recuperado de http://hist.library.paho.org/Spanish/ BOL/v98n2p144.pdf

Jodelet, D. (1984). Représentation sociale: phénomènes, concept et théorie. En S. Moscovici (ed.). Psychologie Sociale (pp. 357-378). París, Francia: Presses Universitaires de France.

Lamborn, S. D., Mounts, N. S., Steinberg, L., y Dornbusch, S. M. (1991). Patterns of competence and adjustment among adolescents from authoritative, authoritarian, indulgent and neglectful families. Child Development, 62(5), 1049-1065. DOI: https://doi.org/10.1111/j.1467-8624.1991.tb01588.x

Mieles, M. D., y García, M. C. (2010). Apuntes sobre socialización infantil y 
construcción de identidad en ambientes multiculturales. Revista Latinoamericana de Ciencias Sociales, Niñez y Juventud, 8(2), 809-819. DOI: https://doi. org/10.11600/1692715x.16215

Maccoby, E. E. y Martin, J. A. (1983). Socialization in the Context of the Family: Parent-Child Interaction. En P. H. Mussen, y E. M. Hetherington (eds.), Handbook of Child Psychology: Vol. 4. Socialization, Personality, and Social Development (pp. 1-101). New York: Wiley.

Moscovici, S. (1984). Psychologie sociale. París, Francia. Presses Universitaires de France.

Ministerio de Educación Nacional. (1997). Lineamientos curriculares de educación preescolar. Bogotá, D. C., Colombia: Ministerio de Educación. DOI: https://doi. org/10.15517/aie.v15i2.18971

Observatorio de Políticas de las Familias OPF. (2015). Tipologías de familias en Colombia: evolución 1993-2014. Documento de trabajo n.o 2016-1. Departamento Nacional de Planeación, Bogotá D. C., Colombia. DOI: https://doi.org/10.2307/j.ctvfc51fp.9

Osorio, A. y Álvarez, A. (2004). Introducción a la salud familiar. Curso Especial de Posgrado en Gestión Local de Salud. San José, Costa Rica: CENDEISSS y Universidad de Costa Rica. DOI: https://doi. org/10.15517/revenf.v0i31.23159

Parra, B. H. (2005). Relaciones que dan origen a la familia. Medellín, Colombia: Universidad de Antioquia. En línea. Recuperado de http://tesis.udea.edu.co/ bitstream/10495/348/1/RelacionesOrigenFamilia.pdf

Pinto, G. J. (2015). Imaginarios sociales de los niños y niñas con relación a la figura paterna (trabajo de grado de especialización).
Universidad Francisco José de Caldas, Bogotá D. C., Colombia. DOI: https:// doi.org/10.33304/revinv.v09n1-2017009

Potter, J. (1998). La representación de la realidad. Discurso, retórica y construcción social. Barcelona, España: Paidós.

Rangel, C. P. E. (2015). Relación entre dinámica familiar y competencia social del niño preescolar de 3 a 5 años (tesis de maestría). Universidad Nacional Mayor de San Carlos, Lima, Perú.

Rico, A. A. (1999). Formas, cambios y tendencias en la organización familiar en Colombia. Revista Nómadas (11), 110117. DOI: https://doi.org/10.30578/nomadas.n45a12

Rich Harris, J. (2002) El mito de la educación. Barcelona, España: Grupo Editorial Random House Mondadori.

Sánchez. E. L. (2008). Crecer con afectos, crecer en familia. Revista Diálogo, 3(10). En línea. https://idus.us.es/xmlui/bitstream/handle/11441/47285/Crecer\%20 con $\% 20$ afectos $\% 20$ crecer\%20en $\% 20$ familia_ESanchezLissen $\% 20$ Revista $\% 20$ Dialogo\%202008-1.pdf?sequence=1\&isAllowed $=y$

Scarpati, P. M., Pertuz, S. M. y Silva, S. A. (2014). Límites, reglas, comunicación en familia monoparental con hijos adolescentes. Diversitas: Perspectivas en Psicología, 10(2), 225-246. DOI: https://doi. org/10.15332/s1794-9998.2014.0002.03

Steinberg, L., Elmen, J. D. y Mounts, N. S. (1989). Authoritative parenting, psychosocial maturity, and academic success among adolescents. Child Development, 60(6), 1424-1436. DOI: https://doi. org/10.2307/1130932

Torío, S., Peña, C. J. y Rodríguez M. M. (2008). Estilos educativos parentales: revisión bibliográfica y reformulación 
teórica. Teoría de la educación. Revista Interuniversitaria, 20. DOI: https://doi. org/10.14201/teoredu2014262

Vasilachis, I. (2003). Pobres, pobreza, identidad y representaciones sociales. Barcelona, España: Gedisa, S. A.

Viveros, E. y Arias, L. (2006). Dinámica interna de las familias con jefatura femenina y menores en conflicto con la ley penal: características interaccionales. Medellín, Colombia: Funlam.
Warash, B. G. y Markstrom, C. A. (2001). Parental perceptions of parenting styles in relation to academic self-esteem of preschoolers. Education, 121(3), 485-493. Winsler, A., Madigan, A. L. y Aquilino, S. A. (2005). Correspondence between maternal and paternal parenting styles in early childhood. Early Childhood Research Quarterly, 20(1) 1-12. DOI: https:// doi.org/10.1016/j.ecresq.2005.01.007 